\title{
Evaluation of Multimodal Anesthetic Drugs Combination undergoing laparo-ovariectomy
}

Elbialy Elmorsy ${ }^{1}$, Khalid S. Abouelnasr ${ }^{2}$, Esam Mosbah ${ }^{2}$, Adel E. Zaghloul ${ }^{2}$

${ }^{1}$ Veterinarian, Veterinary Sector, Dakahlia Governorate, Egypt.

2 Department of Surgery, Anesthesiology and Radiology, Faculty of Veterinary Medicine, Mansoura University, 35516 Mansoura, Egypt.

\section{ARTICLE HISTORY}

\section{Received: 15.10 .2019}

Revised: 11.11.2019

Accepted: 19.11.2019

Address correspondence to Esam Mosbah

; Tel: +201006366762;

E-mail: esamsurgery@gmail.com

esammosbahmohamed@yahoo.com

\section{ABSTRACT}

\begin{abstract}
Objective: To evaluate the effect of multimodal analgesic drugs for alleviation of pain accompanying laparo-ovariectomy in goat .

Design: Randomized controlled experimental study.

Animals: Sixteen goats ageing 8-18 months and weighing $20 \mathrm{~kg}$ on average.

Procedures: The proposed site of laparotomy in all animals was infiltrated with lidocaine hydrochloride $1 \% 15$ minutes before surgery started. The goats were allocated into four groups of four animals each; first group (L): animals received Lidocaine infltration, second group (PL): animals received Piroxicam at a dose rate of $5 \mathrm{mg} / \mathrm{kg} I \mathrm{M}$, third group (PPL): animals received Piroxicam and Propofol at a dose rate of $(5 \mathrm{mg} / \mathrm{kg}$ and $6 \mathrm{mg} / \mathrm{kg}$, respectively), and finally fourth group (PPBL): animals received Butorphanol at a dose rate of $0.1 \mathrm{mg} / \mathrm{kg}$ in addition to Piroxicam-Propofol. Heart rate (HR), respiratory rate (RR), rectal temperature $(R T)$, serum concentrations of lactate, creatinine, blood urea nitrogen $(B \cup N)$, interleukin-6 (IL-6), Alanine aminotransferase (ALT) and Aspartate aminotransferase (AST) were determined at baseline (15 minutes prior to surgery), directly after administration of the anesthetic agent, during surgery, and post-surgery at 30 minutes, 60 minutes, 120 minutes for 1-3 days postoperatively. Additionally, the analgesia score was monitored.

Results: Heart rate, respiratory rate, Serum levels of $I L 6, B U N$ and $A L T$ decreased significantly in $P P B L$ group compared to the other groups $(P \leq 0.05)$. In addition, analgesia scores were significantly higher in PPBL group than the other groups $(P \leq 0.05)$.

Conclusion and clinical relevance: It could be concluded that the use of Propofol and Butorphanol in the analgesic protocol during laparo-ovariectomy in goats can alleviate stress and pain response and could therefore potentiate the effects of local analgesics.
\end{abstract}

Keywords: Lidocaine, Piroxicam, Propofol, Butorphanol, Goats, Laparo-ovariectomy.

\section{INTRODUCTION}

Pain is an unpleasant sensory and emotional experience associated with actual or potential tissue damage, or described in terms of such damage resulting in physiological, neuroendocrine, and behavioural changes that indicate a stress response [1].

Pain is evoked from tissue destruction following laparotomy as well as during wound healing associated with laparo-ovariectomy and inflammatory reaction due to the activation of nociceptors [1, 3].

It has been recommended to combine sedation, local anesthesia and a nonsteroidal anti-inflammatory drugs (NSAID) to obtain optimal pain relief [4]. Piroxicam is a NSAID of the oxicam class, which is nonselective. The mechanism of action of Piroxicam, like any other NSAID, is not completely understood but may be related to prostaglandin synthetase inhibition [5].
Multimodal analgesia is currently recommended for an effective post-operative pain control program. It is achieved by combining different analgesics that act by different mechanisms (opioids, NSAIDs, $\alpha 2$-agonists and local anesthetics) together resulting in a synergistic analgesia, lower total doses of analgesics and minimal side effects [6].

Butorphanol tartrate is a mixed opioid agonist/antagonist that affords good analgesia and mild sedation [7]. It is a very effective drug for providing a pain relief $[8,9]$. Butorphanol has been used in goats to provide intraoperative and postoperative analgesia, that is useful to increase sedation [10]. Butorphanol potency is 5-7 times of morphine [11].

The use of Propofol as a sole anesthetic or in combination with tranquilizers, barbiturates, opioids and inhalant anesthetics has been reported in sheep [12], and goats [13, 14] for short procedures. The aim of this study was therefore to evaluate the comparative effect of multimodal analgesics for alleviation of pain in goats undergoing laparo-ovariectomy. The study will also consider the comparative effect of the 
selected local analgesics on selected cytokine and biochemical parameters in goat.

\section{MATERIALS AND METHODS}

\subsection{Animals, housing and feeding}

Sixteen apparently healthy female goats ageing 8-18 months and with an average body weight of $15-25 \mathrm{~kg}$ were used in the study. All animals were physiologically normal and free from concurrent diseases. They were kept in individual free stalls with straw bedding and were fed a diet based on hay and concentrates. No analgesics were given to the animals within one week before the experiment. Food was withheld for 12 hours and water for 8 hours before laparo-ovariectomy. The study was carried out at Mansoura Veterinary Teaching Hospital, Faculty of Veterinary Medicine, Mansoura University, Mansoura, Egypt. The protocol of the study was approved by the Research Ethics Committee, Faculty of Veterinary Medicine, Mansoura University (REC).

\subsection{Experimental design}

Animals used in this study were randomly assigned into 4 groups of 4 animals each. All goats were infiltrated with lidocaine hydrochloride 1\% (Debocaine 2\%, Al- Debeiky Pharmaceutical Industrial Co, Egypt) 15 minutes before surgery started. Piroxicam (Dispercam, $20 \mathrm{mg} / \mathrm{ml}$, Medical Union Pharmaceuticals, Egypt) was given initially at a dose of 5 $\mathrm{mg} / \mathrm{kg}$ intramuscular at (day 0 ) and was then repeated once daily for another three consecutive days postoperatively in all groups. Animals in the first group (Lidocaine group -L) received linear infiltration of lidocaine at the proposed surgical site (see later) whereas, animals in the second group (PiroxicamLidocaine group -PL) received Piroxicam after lidocaine infiltration. Animals in the third group (Piroxicam- LidocainePropofol group -PLP) received Piroxicam and were then intravenously injected with Propofol $(10 \mathrm{mg} / \mathrm{ml}$ Diprivan $1 \%$, Zeneca Pharmaceuticals, Wilmington, DE) at a dose of $6 \mathrm{mg} / \mathrm{kg}$ at 15 min later. One half to two thirds of the induction dose of Propofol was administered over approximately 30 seconds then an intermittent injection was carried out to maintain anesthesia. Meanwhile, animals in the fourth group (Piroxicam- Butorphanol - Propofol- Lidocaine group -PBPL) received Piroxicam then after $15 \mathrm{~min}$ were administered with butorphanol (Alvegesic PH, $10 \mathrm{mg} / \mathrm{ml}$, CP- Pharm Gmbh, Germany), at a dose of $0.1 \mathrm{mg} / \mathrm{kg}$, then they were intravenously injected by Propofol by the same way as described in the PLP group.

\subsection{Surgical approach}

A $10 \mathrm{~cm}$ midventral laparotomy incision for adequate exposure of the uterus and ovary was done through linea alba in all animals according to standard procedure described previously [15] followed by unilateral ovariectomy (Figure 1).

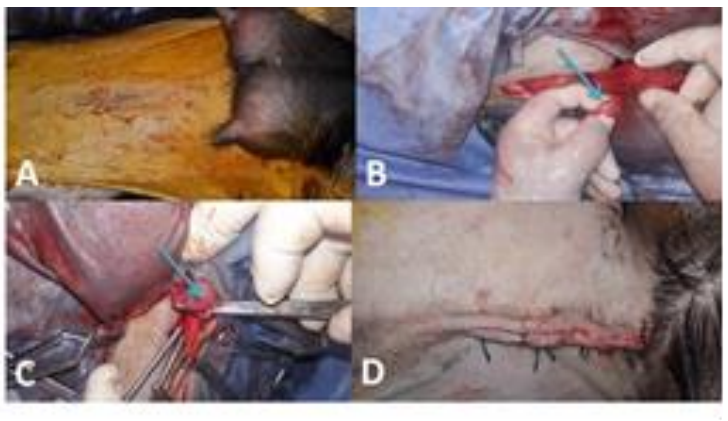

Figure 1. Aseptic preparation of ventral abdominal region in a goat (A), After celiotomy and isolation of left ovary (B), crushing and ligation of ovarianpedicle before ovariectomy $(C)$ and after closure of laparotomy incision.

\subsection{Monitoring}

\subsection{Cardio-respiratory parameters}

HR was measured using stethoscope; RR was measured by counting excoriation/ minute and RT was measured using a digital thermometer.

\subsection{Metabolic and biochemical parameters}

Blood samples were collected and centrifuged at 3000 rpm for 10 minutes, and the separated sera was used for the determination of levels of Interleukin-6 using goat IL-6 ELISA kit (Cusabio Biotech Co, LTD, China), Alanine aminotransferase (ALT) (ALT, Bio diagnostic, Co, Egypt), Aspartate aminotransferase (AST) (AST, Bio diagnostic, Co, Egypt), Lactate (Lactate, Bio Systems S.A., Spain), Urea (Urea, Bio diagnostic, Co, Egypt) and Creatinine (Creatinine, Bio diagnostic, Co, Egypt).

2.4. 3. Analgesia scores: Response of the animals to the surgical procedures was scored according to protocol described before[16, 17] (Table 1).

\subsection{Post-operative care}

All goats were administered Claforan (cefotaxime $50 \mathrm{mg} / \mathrm{kg} /$ twice daily, Sanofi, Egypt) for 5 days. Local antiseptic dressing with povidone iodine was done. Skin sutures were removed 10 days after the operation.

\subsection{Time table}

Baseline values of all measured parameters were determined 15 minutes before the administration of the local analgesics. HR, RR and RT were measured at baseline (15 minutes before surgery), then directly after the administration of anesthetic agent, during surgery (skin incision, during surgery and after end of surgery), and eventually after 30 minutes, 60 minutes, and 120 minutes after surgery and for 13 days postoperatively. Serum blood samples were drawn at the same aforementioned times for the assessment the levels of Inteleukin-6, ALT, AST, Lactate, Urea and Creatinine. 


\subsection{Statistical analysis}

Statistical analyses were carried out using a commercial program (Graph pad prism, version 5.1). A repeated measure ANOVA was performed. When a significant treatment effect was detected, a one-way ANOVA was performed at each time point. Results were considered significant at $\mathrm{P} \leq 0.05$.

Table 1. Scoring system for the degree of analgesia in goat.

\begin{tabular}{cl} 
Score & \multicolumn{1}{c}{ Definition } \\
\hline 4 & $\begin{array}{l}\text { No response to palpation of surgical wound, normal } \\
\text { interaction with environment, normal posture and } \\
\text { movement. }\end{array}$ \\
3 & $\begin{array}{l}\text { Mild response to palpation of surgical wound normal } \\
\text { interaction with environment, occasional vocalization, } \\
\text { normal posture and movement. } \\
\text { Moderate responsive to palpation of surgical wound, } \\
\text { teeth grinding, vocalization, slightly hunched posture and } \\
\text { restricted movement. } \\
\text { Responsive to palpation of surgical wound, vocalization } \\
\text { and rigid posture, does not move freely. }\end{array}$ \\
1
\end{tabular}

\section{RESULTS}

\subsection{Cardio-respiratory findings}

The results of the cardio-respiratory parameters revealed that HR showed significantly higher values in both PL and L treated animals compared to animals in either PPL or PPBL groups, $(P<0.05)$ after the injection of anesthetics and the that the highest value of HR was noted for these animals at $60 \mathrm{~min}$ postoperative. Animals in both PPBL and PPL group displayed a significantly lower values $(\mathrm{P}<0.05)$ of $\mathrm{HR}$ compared to those in both $L$ and $P L$ group, and the lowest values for the HR was recorded at $30 \mathrm{~min}$ post-surgery. Heart rate showed a significant decrease in PPBL group rapidly after the administration of the anesthetics and reached its lowest level at $30 \mathrm{~min}$ postoperative and started to increase thereafter (Table 2).

Similarly, RR showed the same pattern of change as HR. Compared to basal values, mean RR increased significantly $(P<0.05)$ in both $L$ and $P L$ groups after injection of the anesthetics and maintained this persistency until the end of experiment. On the other hand, animals treated with PPBL and PPL combination showed a significant decrease $(P<0.05)$ in $R R$ after injection of the anesthetics and throughout the whole period of study compared to basal values, and the lowest values were recorded at 30 minutes and 60 minutes postsurgery in both PPL group and PPBL group (Table 2).

The effects of the use of anesthetics on the RT showed that the injection of the anesthetics caused a transient increase in $R T$ in $L$ treated animals $(P<0.05)$ compared to animals in the other three groups. There was also a significant increase in values of RT in both $L$ and $P L$ treated animals compared to those in both PPL and PPBL groups at 30 minutes and 60 minutes (Table 2).

\subsection{Metabolic and biochemical analyses}

The results of the metabolic and biochemical parameters showed that in the first day post- surgery the serum levels of AST were significantly higher $(P<0.05)$ in both $P L$ and $L$ treated animals compared to those in either PPBL or PPL groups. However, in the second day post- surgery they changed the other way round where the values of the serum AST were higher in both PPBL and PPL treated animals $(\mathrm{P}<0.05)$ compared to those in either L or PL groups (Table 3). The administration of anesthetic agents caused a significant increase $(P<0.05)$ in values of serum levels of ALT in both $L$ and $\mathrm{PL}$ treated animals compared to those in PPL or PPBL groups during surgery, at the end of surgery, and post-surgery at 30 minutes, 60 minutes and 120 minutes. Whereas at the third day post-surgery the levels of serum ALT were significantly higher in L groups compared to the other three groups, and the highest value of serum ALT was recorded for L groups and the lowest was for the PPBL group (Table 3).

The injection of the anesthetic agents caused a significant increase in the mean values of serum levels of BUN in both $L$ and PPL treated animals $(P<0.05)$ compared to animals either in PL or those in PPBL group at the end of surgery (Table 4). There was also a significant difference in serum levels of BUN between animals in $\mathrm{PL}$ and those in PPBL group $(\mathrm{P}<0.05)$ with highest values were for animals in the $L$ and PPL followed by those in the PPBL group and those in the PPL displayed the lowest values at the end of surgery (Table 4). However, at 30 minutes and 60 minutes post-surgery the animals in the $L$ group scored higher values $(\mathrm{P}<0.05)$ compared to the in the other three groups. On the other hand, the use of anesthetic agents did not significantly affect the levels of serum creatinine in all treated groups at any time point

The use of anesthetic agents caused the same pattern of change in the serum levels of lactate throughout the different time points of the study except at the third day post-surgery. The serum lactate levels were always significantly higher $(P<0.05)$ in those animals treated with either $P L$ or $L$ compared to those in both PPL and PPBL groups during and at the end of surgery, and then at 30 minutes, 60 minutes, 120 minutes, at first day and at second day post- surgery (Table 5). Whereas, at the third day post-surgery the levels of serum lactate were higher in animals of L, PL and PPL compared to those animals in the PPBL group.

Serum levels of IL6 were significantly $(P<0.05)$ higher in both $L$ and PL treated animals compared to both PPL and PPBL 
treated animals during and at the end of surgery. Whereas, at 30 minutes, 60 minutes and 120 minutes post-surgery animals of the L group showed significantly higher levels of serum IL6 $(P<0.05)$ compared to those in the other three groups. In the second day post-surgery animals in the PPBL groups displayed the highest level of serum IL6 when compared to the other groups (Table 5).

\subsection{Analgesia score}

Table.2. Heart rate, respiratory rate and rectal temperature (Mean $\pm S D$ ) in goats injected with Lidocaine (L), Piroxicam - Lidocaine (PL), PiroxicamPropofol - Lidocaine (PPL) and Piroxicam- Propofol - Butorphanol, Lidocaine (PPBL) for laparo-ovariectomy.

\begin{tabular}{|c|c|c|c|c|c|c|c|c|c|c|}
\hline \multirow[b]{2}{*}{ Variable } & \multicolumn{2}{|c|}{ Surgery } & \multirow[b]{2}{*}{ During } & \multirow[b]{2}{*}{ End } & \multicolumn{6}{|c|}{ Post -surgery } \\
\hline & group & Base line & & & $30 \mathrm{~min}$ & $60 \mathrm{~min}$ & $120 \mathrm{~min}$ & 1 day & 2 day & 3 day \\
\hline \multirow{4}{*}{$\begin{array}{l}\text { Heart rate } \\
\text { (beat/ min) }\end{array}$} & L & $130.3 \pm 2.6$ & $134.3 \pm 4.3$ & $138.8 \pm 1.9^{a}$ & $143.3 \pm 5.2^{\text {a }}$ & $141.3 \pm 2.2^{\mathrm{a}}$ & $137.0 \pm 1.4^{\mathrm{a}}$ & $130.0 \pm 7.3^{\text {a }}$ & $126.8 \pm 8.0^{\text {a }}$ & $129.8 \pm 3.3^{a}$ \\
\hline & PL & $129.0 \pm 1.9$ & $132.3 \pm 5.4$ & $136.3 \pm 3.9$ a. b & $139 \pm 0.9^{a}$ & $135.0 \pm 4.8^{a}$ & $138.3 \pm 2.2^{\mathrm{a}}$ & $132.0 \pm 1.6^{a}$ & $130.3 \pm 2.1^{a}$ & $129.0 \pm 2.6^{a}$ \\
\hline & PPL & $138.5 \pm 7.9$ & $134.3 \pm 7.5$ & $130.8 \pm 4.9^{b}$ & $122.8 \pm 4.4^{b}$ & $119.3 \pm 8.9^{b}$ & $122.0 \pm 9.5^{b}$ & $126.7 \pm 9.5^{\text {a }}$ & $130.8 \pm 8.9^{\text {a }}$ & $131.0 \pm 5.5^{\mathrm{a}}$ \\
\hline & PPBL & $131.0 \pm 3.9$ & $126.5 \pm 3.7$ & $122.8 \pm 4.1^{b}$ & $115.0 \pm 5.7^{b}$ & $110.8 \pm 8.8^{b}$ & $115.0 \pm 6.4^{b}$ & $124.0 \pm 8.0^{\mathrm{a}}$ & $122.7 \pm 4.3^{\text {a }}$ & $120.0 \pm 4.8^{b}$ \\
\hline \multirow{5}{*}{$\begin{array}{l}\text { Respiratory } \\
\text { rate } \\
\text { (breath/ min) }\end{array}$} & L & $20.3 \pm 3.2$ & $22.3 \pm 2.5$ & $24.0 \pm 1.6^{a}$ & $24.3 \pm 2.1^{\mathrm{a}}$ & $25.3 \pm 2.2^{a}$ & $24.0 \pm 1.6^{a}$ & $23.8 \pm 3.4^{a}$ & $23.3 \pm 3.4^{\mathrm{a}}$ & $23.0 \pm 4.3^{a}$ \\
\hline & PL & $19.5 \pm 2.1$ & $22.5 \pm 0.6$ & $25.5 \pm 1.3^{\text {a }}$ & $24.8 \pm 0.9^{a}$ & $24.3 \pm 1.3^{a}$ & $24.0 \pm 2.1^{a}$ & $21.8 \pm 3.2^{\mathrm{a}, \mathrm{b}}$ & $22.3 \pm 0.5^{a}$ & $21.0 \pm 2.2^{\mathrm{a}}$ \\
\hline & PPL & $21.5 \pm 3.1$ & $19.8 \pm 2.4$ & $19.5 \pm 2.6^{b}$ & $16.3 \pm 0.5^{b}$ & $12.5 \pm 2.1^{b}$ & $12.5 \pm 3.1^{b}$ & $16.8 \pm 3.5^{b, c}$ & $18.0 \pm 4.1^{\mathrm{a}, \mathrm{b}}$ & $18.8 \pm 2.4^{a}$ \\
\hline & PPBL & $23 \pm 3.2$ & $21.5 \pm 3.7$ & $20.0 \pm 2.9^{b}$ & $15.5 \pm 2.6^{b}$ & $12.8 \pm 2.1^{b}$ & $12.8 \pm 3.1^{b}$ & $13.0 \pm 2.2^{c}$ & $15.8 \pm 2.2^{b}$ & $18.0 \pm 2.7^{a}$ \\
\hline & $\mathrm{L}$ & $38.7 \pm 0.5$ & $38.8 \pm 0.3$ & $39.0 \pm 0.1^{a}$ & $39.0 \pm 1.8$ & $39.2 \pm 0.4^{a}$ & $39.1 \pm 0.2^{a}$ & $38.7 \pm 0.1$ & $38.7 \pm 0.2$ & $38.7 \pm 0.2$ \\
\hline \multirow{3}{*}{$\begin{array}{l}\text { Rectal } \\
\text { Temperature } \\
\text { (으) }\end{array}$} & PL & $39.0 \pm 0.3$ & $39.0 \pm 0.4$ & $39.1 \pm 0.2^{b}$ & $39.0 \pm 0.2$ & $39.1 \pm 0.5^{a}$ & $39.1 \pm 0.2^{\mathrm{a}}$ & $38.8 \pm 0.1$ & $38.8 \pm 0.1$ & $38.9 \pm 0.1$ \\
\hline & PPL & $39.2 \pm 0.4$ & $38.9 \pm 0.3$ & $38.6 \pm 0.3^{b}$ & $38.3 \pm 0.5$ & $37.8 \pm 0.5^{b}$ & $37.8 \pm 0.5^{b}$ & $38.4 \pm 0.4$ & $38.6 \pm 0.2$ & $38.8 \pm 0.3$ \\
\hline & PPBL & $39.4 \pm 0.6$ & $39.3 \pm 0.7$ & $39.1 \pm 0.8^{b}$ & $38.4 \pm 0.5$ & $37.6 \pm 0.6^{b}$ & $37.9 \pm 0.6^{b}$ & $38.5 \pm 0.6$ & $38.7 \pm 0.2$ & $38.8 \pm 0.2$ \\
\hline
\end{tabular}

Means within the same column with different superscript litters are significantly different at $\mathrm{P}<0.05$

Table 3. Serum ALT and AST activity (Mean \pm SD) in goats injected with Lidocaine (L), Piroxicam - Lidocaine (PL), Piroxicam - Propofol - Lidocaine (PPL) and Piroxicam- Propofol - Butorphanol, Lidocaine (PPBL) for laparo-ovariectomy.

\begin{tabular}{|c|c|c|c|c|c|c|c|c|c|c|}
\hline \multirow[b]{2}{*}{ Variable } & \multicolumn{4}{|c|}{ Surgery } & \multicolumn{6}{|c|}{ Post -surgery } \\
\hline & group & Base line & During & End & $30 \mathrm{~min}$ & $60 \mathrm{~min}$ & $120 \mathrm{~min}$ & 1 day & 2 day & 3 day \\
\hline \multirow[t]{4}{*}{ AST (mg/dl) } & $\mathrm{L}$ & $25.8 \pm 1.7$ & $29.0 \pm 5.4$ & $28.8 \pm 3.3$ & $29.3 \pm 2.1$ & $30.3 \pm 1.7$ & $30.8 \pm 2.1$ & $33.8 \pm 2.1^{a}$ & $31.0 \pm 2.4^{b}$ & $31.8 \pm 3.4$ \\
\hline & PL & $28.5 \pm 4.1$ & $30.8 \pm 1.3$ & $29.3 \pm 2.5$ & $30.7 \pm 2.1$ & $31.5 \pm 4.2$ & $32.5 \pm 7.4$ & $36.3 \pm 6.3^{a}$ & $32.5 \pm 2.5^{b}$ & $36.0 \pm 6.1$ \\
\hline & PPL & $25.5 \pm 2.6$ & $30.0 \pm 3.7$ & $23.8 \pm 6.9$ & $27.0 \pm 6.1$ & $31.8 \pm 1.9$ & $27.3 \pm 3.5$ & $25.8 \pm 4.3^{b}$ & $25.3 \pm 1.5^{\mathrm{a}}$ & $26.5 \pm 1.3$ \\
\hline & PPBL & $25.3 \pm 2.6$ & $28.0 \pm 6.1$ & $23.0 \pm 7.8$ & $25.8 \pm 5.3$ & $26.8 \pm 5.2$ & $27.0 \pm 3.9$ & $29.0 \pm 5.6^{b}$ & $25.5 \pm 2.6^{a}$ & $27.5 \pm 6.5$ \\
\hline \multirow[t]{4}{*}{ ALT (mg/dl) } & L & $107.5 \pm 7.1$ & $122.8 \pm 6.6^{a}$ & $125.3 \pm 9.6^{\mathrm{a}}$ & $131.8 \pm 8.2^{\mathrm{a}}$ & $134.8 \pm 6.4^{a}$ & $136.5 \pm 19.2^{\mathrm{a}}$ & $130.3 \pm 19.9$ & $124.3 \pm 19.1$ & $122.8 \pm 8.5^{a}$ \\
\hline & PL & $106.3 \pm 8.8$ & $120.0 \pm 5.6^{a}$ & $125.0 \pm 10.7^{a}$ & $134.3 \pm 17.3^{a}$ & $136.0 \pm 5.2^{a}$ & $130.5 \pm 25.9^{\text {a }}$ & $134.0 \pm 28.4$ & $133.5 \pm 29.5$ & $131.8 \pm 19.3$ \\
\hline & PPL & $99.5 \pm 14.2$ & $84.3 \pm 7.8^{b}$ & $79.5 \pm 2.6^{b}$ & $102.8 \pm 32.4^{a, b}$ & $102.3 \pm 27.8^{b}$ & $105.5 \pm 22.1^{a, b}$ & $120.0 \pm 40.6$ & $107.0 \pm 21.4$ & ${ }_{c}^{99.8 \pm 19.9 b,}$ \\
\hline & PPBL & $98.8 \pm 6.2$ & $93.8 \pm 5.3^{b}$ & $87.5 \pm 5.7^{b}$ & $81.8 \pm 5.3^{b}$ & $83.0 \pm 4.2^{b}$ & $88.5 \pm 4.2^{b}$ & $91.5 \pm 1.0$ & $89.8 \pm 8.5$ & $90.3 \pm 6.4^{c}$ \\
\hline
\end{tabular}

Means within the same column with different superscript litters are significantly different at $P<0.05$

All within interaction, Wilks' Lambda, $\mathrm{P}<0.0611$; Within time, Wilks' Lambda, $\mathrm{P}<0.001$; Time * groups, Wilks' Lambda, $\mathrm{P}<0.0611$ 
Table 4. Serum BUN, Creatinine (Mean \pm SD) in goats injected with Lidocaine (L), Piroxicam - Lidocaine (PL), Piroxicam - Propofol - Lidocaine (PPL) and Piroxicam- Propofol - Butorphanol, Lidocaine (PPBL) for laparo-ovariectomy.

\begin{tabular}{|c|c|c|c|c|c|c|c|c|c|c|}
\hline \multirow[b]{2}{*}{ Variables } & \multirow[b]{2}{*}{ group } & \multirow[b]{2}{*}{ Base line } & \multicolumn{4}{|c|}{ Surgery } & \multicolumn{4}{|c|}{ Post-surgery } \\
\hline & & & During & End & $30 \mathrm{~min}$ & $60 \mathrm{~min}$ & $120 \mathrm{~min}$ & 1 day & 2 day & 3 day \\
\hline \multirow{4}{*}{$\begin{array}{l}\text { BUN } \\
\text { (mg/dl) }\end{array}$} & $\mathrm{L}$ & $60.50 \pm 4.20$ & $67.25 \pm 3.40$ & $69.50 \pm 3.42^{a}$ & $77.50 \pm 5.57^{a}$ & $68.00 \pm 6.83^{a}$ & $56.25 \pm 5.68$ & $55.25 \pm 2.36$ & $60.50 \pm 6.86$ & $60.25 \pm 2.63$ \\
\hline & $\mathrm{PL}$ & $64.75 \pm 5.12$ & $51.00 \pm 4.69$ & $44.75 \pm 8.54^{c}$ & $51.50 \pm 9.11^{b}$ & $55.75 \pm 9.25^{a, b}$ & $52.75 \pm 3.50$ & $49.00 \pm 8.64$ & $57.75 \pm 5.50$ & $60.25 \pm 4.99$ \\
\hline & PPL & $51.50 \pm 6.45$ & $58.00 \pm 6.00$ & $59.50 \pm 6.86^{a}$ & $58.75 \pm 8.30^{a, b}$ & $56.00 \pm 5.89^{b}$ & $53.75 \pm 6.08$ & $54.50 \pm 8.66$ & $51.25 \pm 9.88$ & $51.00 \pm 6.73$ \\
\hline & PPBL & $60.75 \pm 5.62$ & $52.75 \pm 6.08$ & $48.25 \pm 6.70^{b}$ & $44.00 \pm 8.04^{b, c}$ & $44.75 \pm 3.77^{b}$ & $53.50 \pm 4.12$ & $55.00 \pm 4.24$ & $55.50 \pm 5.00$ & $60.25 \pm 5.38$ \\
\hline \multirow{4}{*}{$\begin{array}{l}\text { Creatinine } \\
\text { (mg/dl) }\end{array}$} & $\mathrm{L}$ & $1.18 \pm 0.22$ & $1.33 \pm 0.39$ & $1.03 \pm 0.21$ & $1.18 \pm 0.17$ & $0.93 \pm 0.15$ & $1.08 \pm 0.17$ & $1.15 \pm 0.26$ & $1.35 \pm 0.19$ & $0.90 \pm 0.29$ \\
\hline & $\mathrm{PL}$ & $1.10 \pm 0.18$ & $1.05 \pm 0.17$ & $0.88 \pm 0.25$ & $0.98 \pm 0.10$ & $1.03 \pm 0.10$ & $1.15 \pm 0.19$ & $1.15 \pm 0.21$ & $1.18 \pm 0.22$ & $2.98 \pm 4.03$ \\
\hline & PPL & $0.97 \pm 0.23$ & $1.08 \pm 0.13$ & $1.05 \pm 0.13$ & $1.15 \pm 0.10$ & $0.88 \pm 0.10$ & $1.03 \pm 0.15$ & $0.90 \pm 0.24$ & $1.01 \pm 0.14$ & $0.88 \pm 0.13$ \\
\hline & PPBL & $0.95 \pm 0.14$ & $1.02 \pm 0.16$ & $1.00 \pm 0.14$ & $1.15 \pm 0.10$ & $0.84 \pm 0.11$ & $1.03 \pm 0.15$ & $0.88 \pm 0.28$ & $1.01 \pm 0.14$ & $0.82 \pm 0.09$ \\
\hline
\end{tabular}

Means within the same column with different superscript litters are significantly different at $\mathrm{P}<0.05$

All within interaction, Wilks' Lambda, $\mathrm{P}<0.4754$; Within time, Wilks' Lambda, $\mathrm{P}<0.001$; Time * groups, Wilks' Lambda, $\mathrm{P}<0.475$

Table 5. Serum Lactate and Interleukin- 6 (Mean \pm SD) in goats injected with Lidocaine (L), Piroxicam - Lidocaine (PL), Piroxicam - Propofol Lidocaine (PPL) and Piroxicam- Propofol - Butorphanol, Lidocaine (PPBL) for laparo-ovariectomy.

\begin{tabular}{|c|c|c|c|c|c|c|c|c|c|c|}
\hline \multicolumn{5}{|c|}{ Surgery } & \multicolumn{6}{|c|}{ post-surgery } \\
\hline Variable & groups & basal & during & End & $30 \mathrm{~min}$ & $60 \mathrm{~min}$ & $120 \mathrm{~min}$ & 1 day & 2 day & 3 day \\
\hline \multirow{4}{*}{$\begin{array}{l}\text { Lactate } \\
\text { (mg/dl) }\end{array}$} & L & $55.1 \pm 4.9$ & $64.1 \pm 5.6^{a}$ & $68.1 \pm 3.1^{a}$ & $72.1 \pm 3.6^{a}$ & $64.6 \pm 6.0^{a}$ & $55.1 \pm 5.7^{a}$ & $49.6 \pm 4.6^{a}$ & $51.0 \pm 5.6^{a}$ & $51.7 \pm 4.5^{a}$ \\
\hline & PL & $59.5 \pm 3.9$ & $67.2 \pm 5.7^{\mathrm{a}}$ & $73.4 \pm 4.3^{a}$ & $79.0 \pm 2.5^{\text {a }}$ & $64.6 \pm 6.1^{\mathrm{a}}$ & $55.1 \pm 5.4^{\mathrm{a}}$ & $51.1 \pm 4.8^{a}$ & $51.1 \pm 3.2^{\mathrm{a}}$ & $58.1 \pm 1.9^{a}$ \\
\hline & PPL & $63.8 \pm 3.7$ & $48.4 \pm 3.2^{b}$ & $45.5 \pm 5.8^{b}$ & $43.8 \pm 8.1^{b}$ & $43.1 \pm 6.6^{b}$ & $44.1 \pm 2.0^{b}$ & $43.4 \pm 5.3^{a, b}$ & $38.0 \pm 2.1^{b}$ & $54.5 \pm 5.7^{a}$ \\
\hline & PPBL & $58.8 \pm 5.5$ & $50.7 \pm 6.6^{b}$ & $39.5 \pm 6.6^{b}$ & $42.1 \pm 12.4^{b}$ & $42.1 \pm 4.6^{b}$ & $43.7 \pm 4.2^{b}$ & $37.8 \pm 6.9^{b}$ & $33.4 \pm 6.7^{b}$ & $40.8 \pm 2.9^{b}$ \\
\hline \multirow[t]{4}{*}{$\begin{array}{l}\text { Interleukin- } 6 \\
\text { (pg/ml) }\end{array}$} & L & $5.5 \pm 1.3$ & $6.7 \pm 0.9^{a}$ & $7.1 \pm 0.8^{a}$ & $6.4 \pm 2.4^{\mathrm{a}}$ & $\begin{array}{c}6.8 \pm 1.2 \\
a\end{array}$ & $5.1 \pm 1.2^{\mathrm{a}}$ & $5.9 \pm 1.9$ & $5.6 \pm 1.2^{\mathrm{a}}$ & $5.9 \pm .4$ \\
\hline & PL & $5.1 \pm 0.9$ & $6.00 \pm 1.1^{\mathrm{a}}$ & $6.2 \pm 1.2^{\mathrm{a}}$ & $6.9 \pm 1.3^{b}$ & $\underset{b}{6.2 \pm 0.7}$ & $5.1 \pm 0.7^{b}$ & $5.5 \pm 0.2$ & $5.7 \pm 1.1^{\mathrm{a}}$ & $5.4 \pm 0.7$ \\
\hline & PPL & $5.4 \pm 0.9$ & $4.7 \pm 0.8^{a, b}$ & $4.4 \pm 0.5^{b}$ & $4.7 \pm 0.7^{a, b}$ & $\underset{a, b}{5.2 \pm 0.8}$ & $5.6 \pm 0.9^{a}$ & $5.8 \pm 0.8$ & $5.9 \pm 0.78^{a}$ & $6.2 \pm 0.8$ \\
\hline & PPBL & $4.6 \pm 1.3$ & $4.1 \pm 1.2^{b}$ & $3.7 \pm 0.8^{b}$ & $3.6 \pm 0.5^{b}$ & $\underset{b}{4.5 \pm 1.1}$ & $5.2 \pm 0.9^{b}$ & $5.7 \pm 0.1$ & $5.2 \pm 0.5^{b}$ & $5.6 \pm 1.5$ \\
\hline
\end{tabular}

Means within the same column with different superscript litters are significantly different at $P<0.05$

All within interaction, Wilks' Lambda, $\mathrm{P}<0.0481$; Within time, Wilks' Lambda, $\mathrm{P}<0.001$; Time * groups, Wilks' Lambda, $\mathrm{P}<0.0481$

Table 6. Analgesia scores (Mean \pm SD) in goats injected with Lidocaine (L), Piroxicam - Lidocaine (PL), Piroxicam - Propofol - Lidocaine (PPL) and Piroxicam- Propofol - Butorphanol, Lidocaine (PPBL) for laparo-ovariectomy.

\begin{tabular}{|c|c|c|c|c|c|c|c|}
\hline \multirow[t]{2}{*}{ Groups } & \multicolumn{4}{|c|}{ Surgery } & \multicolumn{3}{|c|}{ Post-surgery } \\
\hline & Base line & $\begin{array}{l}\text { After injection of } \\
\text { anesthetic agent }\end{array}$ & Start of surgery & End of surgery & $30 \mathrm{~min}$ & $60 \mathrm{~min}$ & $120 \mathrm{~min}$ \\
\hline $\mathrm{L}$ & $0.0 \pm 0.0$ & $1.25 \pm 0.50^{a}$ & $2.00 \pm 0.00^{a}$ & $1.75 \pm 0.50^{a}$ & $1.3 \pm 0.5^{a}$ & $1.0 \pm 0.0^{a}$ & $1.0 \pm 0.0^{a}$ \\
\hline $\mathrm{PL}$ & $0.0 \pm 0.0$ & $1.75 \pm 0.50^{a}$ & $2.50 \pm 0.6^{a}$ & $2.75 \pm 0.50^{a}$ & $2.25 \pm 0.6^{a}$ & $2.3 \pm 0.5^{a}$ & $1.75 \pm 0.5^{b}$ \\
\hline PPL & $0.0 \pm 0.0$ & $3.00 \pm 0.00^{b}$ & $3.50 \pm 0.6^{b}$ & $4.0 \pm 0.0^{b}$ & $3.75 \pm 0.5^{b}$ & $2.5 \pm 0.6^{a}$ & $2.3 \pm 0.5^{a, b}$ \\
\hline PPBL & $0.0 \pm 0.0$ & $3.25 \pm 0.50^{b}$ & $3.50 \pm 0.6^{b}$ & $4.0 \pm 0.0^{b}$ & $4.00 \pm 0.0^{c}$ & $3.0 \pm 0.0^{b}$ & $2.3 \pm 0.5^{b}$ \\
\hline
\end{tabular}

Means within the same column with different superscript litters are significantly different at $\mathrm{P}<0.05$

All within interaction, Wilks' Lambda, $\mathrm{P}<0.0398$; Within time, Wilks' Lambda, $\mathrm{P}<0.001$; Time * groups, Wilks' Lambda, $\mathrm{P}<0.0398$ 


\section{DISCUSSION}

The combination of butorphanol and propofol in this study offered advantages over the use of either drug alone. These advantages include the use of low doses of the drugs which in turn could induce less cardiopulmonary side effects in goats while providing adequate sedation and analgesia. Combining butorphanol with propofol in goats undergoing laparo-ovariectomy reduced on one hand HR and RR and on the other hand induced good analgesia. Also, the use of the combination increased levels of IL6 in treated animals until 30 minutes post-surgery.

Heart rate in lidocaine treated animals (control group) increased until the end of operation. This result could be attributed to the sympathetic nerve block and vasodilatation induced by the lidocaine $[18,19]$. The increase in HR during anesthesia might be due to the increase in myocardial blood flow or the stimulation of cardio excitatory centers of brain or sympathetic nervous system [20].

The finding that HR decreased significantly in PPBL treated goats until the end of surgery may have resulted from cardiovascular and respiratory depressant effect of butorphanol, and this result agrees with that reported previously $[8,17]$. The reason of the increase in HR following administration of butorphanol in goats could be the relaxation of vascular musculature [16].

In the present study, RR increased significantly after lidocaine administration during surgical intervention. A similar increase in RR has been reported in lambs received a combination of lidocaine and tramadol [19]. It has been reported that lidocaine increase RR through sympathetic nerve block and vasodilatation [18]. In the present study, a reduction in RR was reported in all animals of PPL and PPBL groups during surgical intervention. Respiratory depression associated with the administration of propofol and butorphanol might be secondary to the CNS depression produced by alpha-2 adrenoceptor stimulation [21], or to the direct depression of the respiratory centers by pre-anesthetics [22].

In the present study, the quality of analgesia ranged from good to excellent in PPL and PPBL treated animals up to 30 minutes post-surgery. Piroxicam produces the analgesic effect through its binding properties, inhibition of COX-2 enzymes, and is successfully used in goats [23]. Repeated successive intramuscular injection of piroxicam achieved effective analgesia in the postsurgical period. Meloxicam has both analgesic and anti-inflammatory properties and may be used to complement the local anesthesia during and after surgical intervention on the bovine digit post-surgery [24].

Serum ALT concentrations increased significantly after laparo-ovariectomy, indicating an important alteration in animal perception of pain and consequently an impact of animal welfare. The stress response was reflected by a rise in serum ALT during surgery in both L and PL groups. Addition of piroxicam reduced the perioperative levels of stress-related hormones which was represented in a reduction in serum ALT levels [25].

PPBL is regarded as the most effective analgesic regimen in ovariectomy in goats due to the analgesic effect of butorphanol and piroxicam. This finding is supported by findings of previous work on anesthetics $[21,26]$. However, the stress response of surgical procedures cannot be completely suppressed by the synergistic effect of lidocaine, piroxicam, propofol and butorphanol. This finding agreed with [27].

Interleukin- 6 is secreted by a wide range of cells including immune cells, fibroblasts, endothelial cells, and neurons. It is one of the most common cytokines that induces hyperalgesia [28]. The preemptive use of lidocaine treatment in the current study had no significant effect in attenuation of IL-6. It has been previously found that lidocaine did not abolish pain associated with surgery and the strong stimulation of nociceptors during the surgical treatment led to a direct release of cytokines into the blood stream which subsequently triggered an endocrine stress response [18] and this finding agrees with the result of the current study. IL6 causes production of cyclooxygenase 2 (small mediators) which generates PGE2 that causes vasodilatation therefore enhancing the perception of pain [29]. In the present study, the inclusion of piroxicam in the anesthesia regimen had a significant effect in the attenuation of serum IL- 6 during and post-surgery in PPL and PPBL groups. This may be due to the reduction of inflammatory cells production that are responsible for IL-6 secretion after surgical incision [30, 31].

The preemptive combination of propofol-piroxicambutorphanol resulted in augmentation of the attenuation of serum IL-6. Butorphanol was able to increase the ability of piroxicam to inhibit prostaglandin synthesis via the blockage of cyclooxygenase and the prevention of cytokines induced hyperalgesia [23]. This result agrees with the previous findings that reported that stimulation of serotonergic descending inhibitory system resulted in a decreased stimulation of lymphocyte proliferation and a decrease in IL-6 production [32].

In the present study, serum lactate increased significantly until 60 min post-surgery in L and PL treated animals but tended to persist high in lidocaine treated animals. This could be attributed to the stress induced by surgical intervention. A mild increase in blood lactate concentrations was reported in cattle during abdominal and digit surgery and was attributed to stress induced vasoconstriction and reduced tissue oxygenation $[33,34,36]$. The increase in serum lactate activity may be attributed to the possibility of muscle damage [35]. Plasma lactate levels remained lower in goats of PPBL group than in lidocaine groups. This finding also agrees with previous 
results reported that plasma lactate remained on average lower in cows treated with xylazine than in controls animals received saline solution during claw surgery in cattle [36].

The results of the non-significant increase in BUN and creatinine values might be attributed to a temporary inhibitory effect of the drug on the renal blood flow, which in turn might have caused a rise in BUN and creatinine [37]. In the current study a significant increase of BUN in PL group was observed, and a significant decrease during surgery and anesthesia in PPL and PPBL group. Similarly, a non-significant increase in BUN level at different stages of surgical anesthesia in dogs receiving BAG-Propofol anesthesia has been reported previously [38].

Serum creatinine concentrations increased significantly after ovariectomy, indicating an important alteration in animal welfare and perception of pain. A significant increase in creatinine levels were reported in animals of PPL and PPBL groups during the operation and were followed by a decrease reaching to the pre-operative levels 48 hours postoperatively. The finding is similar to that reported previously in dogs anaesthetized with BAG-Propofol [20]. The values of creatinine were transiently and non-significantly increased at initial intervals after administration of propofol, which returned towards the base value by end of observation [39].

The stress response was reflected by a rise in serum creatinine during surgery in all groups of goats. In addition, increased hepatic urea production from amino acid degradation could account for the observed increase in BUN values as was recorded previously [40]. Similar changes in BUN were also reported after the administration of butorphanol in goat [41]. Blood urea nitrogen and creatinine were elevated postoperatively in calves with obstructive urolithiasis due to retention of urine and the onset of acute renal failure which was manifested by a decreased glomerular filtration rate as a result of back pressure on the kidneys [42].

Goats in PPL and PPBL groups showed good to excellent state of analgesia with reduced levels of serum lactate, BUN and IL6 with a significant increase in serum creatinine.

\section{CONCLUSION}

The results of the present study indicate that the addition of piroxicam to the analgesic protocol in goats undergoing laparo-ovariectomy can alleviate surgical stress and may therefore achieve sufficient analgesic effects.

\section{Conflict of interest}

The authors have no conflict of interest.

\section{Research Ethics Committee permission}

The study was carried out according to the requirements of the Research Ethics Committee, Faculty of Veterinary Medicine, Mansoura University.

\section{Funding}

The study received no fund from any particular bodies including public or commercial agencies, and was not for profit.

\section{Authors' contribution}

Esam Mosbah conducted the experimental study, Elbialy Elmorsy drafted the manuscript and revised the data, and Adel Zaghloul revised the manuscript.

\section{REFERANCES}

[1] Zimmermann M. Pathobiology of neuropathic pain. European J Pharmacol 2001;429:23-37.

[2] Coetzee JF. A review of analgesic compounds used in food animals in the United States. Vet Clin North Am Food Anim Pract 2013 29:11-28.

[3] Molony V, Kent JE. Assessment of acute pain in farm animals using behavioral and physiological measurements. J Anim Sci 1997;75:266.

[4] Anderson DE, Muir WW. Pain Management in Cattle. Vet Clin North Am Food Anim Pract 2005;21:623-35.

[5] Abedullahh MHJ. Design and development of piroxicam-entrapped niosomes as an oral drug delivery system: Internat J Advan Pharmaceut Res 2013

[6] Coetzee JF. A review of pain assessment techniques and pharmacological approaches to pain relief after bovine castration: Practical implications for cattle production within the United States. Appl Anim Behav Sci 2011;135:192-213.

[7] Thurmon J. Preanesthetic adjuncts. Lumb Jones' veterinary anesthesia, 3rd ed. Wiley 1996

[8] DeRossi R, Almeida RG, Medeiros U, Righetto FR, Frazílio FO. Subarachnoid butorphanol augments lidocaine sensory anaesthesia in calves.V J 2007;173:658-63.

[9] Bodnar RJ. Endogenous opiates and behavior: 2008. Peptides. 2009;30:2432-79.

[10] Dzikiti TB, Stegmann GF, Dzikiti LN, Hellebrekers LJ. Effects of midazolam on isoflurane minimum alveolar concentration in goats. Small Ruminant Research. 2011;97:104-9.

[11] KuKanich B, Papich MG. Pharmacokinetics of tramadol and the metabolite O-desmethyltramadol in dogs. J Vet Pharmacol Ther 2004;27:239-46.

[12] Singh L, Shivaprakash B, Usturge S, Dilipkumar DJIJVS. of Indian Society for Veterinary Surgery and National Symposium (November 20-22 2003). 2003;24:121-41.

[13] Reid J, Nolan AM, Welsh E. Propofol as an induction agent in the goat: a pharmacokinetic study. Journal of Veterinary Pharmacology and Therapeutics. 1993;16:488-93.

[14] Singh NK, Pandey R, Singh BJIJoVS. A note on propofol anaesthesia in sheep. Indian j vet Res 2003;24:106

[15] Ames NK. Noordsy's Food Animal Surgery: John Wiley \& Sons; 2013.

[16] Carroll GL, Boothe DM, Hartsfield SM, Waller MK, Geller SC. Pharmacokinetics and selected behavioral responses to butorphanol and its metabolites in goats following intravenous and intramuscular administration. Vet Anaesth Analg 2001;28:188-95.

[17] Hamed M, Rizk A, Mosbah E, Abonorg M, Karrouf G. Evaluation of Different Anesthetic Drugs Combination for Pain Management in Goats Undergoing Global Veterinaria 2015;14:151-61.

[18] Doherty TJ, Kattesh HG, Adcock RJ, Welborn MG, Saxton AM, Morrow JL, et al. Effects of a Concentrated Lidocaine Solution on the Acute Phase Stress Response to Dehorning in Dairy Calves. J Dairy Sci 2007;90:4232-9.

[19] Habibian S, Bigham AS, Aali E. Comparison of lidocaine, tramadol, and lidocaine-tramadol for epidural analgesia in lambs. ResVet Sci 2011;91:434-8

[20] Singh GD, Kinjavdekar P, Amarpal, Aithal HP, Pawde AM, Zama MMS, et al. Clinicophysiological and haemodynamic effects of fentanyl with xylazine, medetomidine and dexmedetomidine in isofluraneanaesthetised water buffaloes (<i>Bubalus bubalis</i>). JSAVA 2013;84. 
[21] Sinclair MDJTCvj. A review of the physiological effects of $\alpha 2$-agonists related to the clinical use of medetomidine in small animal practice. Can Vet J 2003;44:885.

[22] Carroll GL, Hooper RN, Slater MR, Hartsfield SM, Matthews NS. Detomidine-Butorphanol-Propofol for Carotid Artery Translocation and Castration or Ovariectomy in Goats. Vet Surg 1998;27:75-82.

[23] Ingvast-Larsson C, HÖGberg M, Mengistu U, OlsÉN L, Bondesson U, Olsson K. Pharmacokinetics of meloxicam in adult goats and its analgesic effect in disbudded kids. J Vet Pharmacol Ther 2011;34:64-9.

[24] Offinger J, Herdtweck S, Rizk A, Starke A, Heppelmann M, Meyer H, et al. Postoperative analgesic efficacy of meloxicam in lame dairy cows undergoing resection of the distal interphalangeal joint. J Dairy Sci 2013;96:866-76.

[25] Heinrich A, Duffield TF, Lissemore KD, Squires EJ, Millman ST. The impact of meloxicam on postsurgical stress associated with cautery dehorning. J Dairy Sci 2009;92:540-7.

[26] Shukla M, Singh G, Sindhura BG, Telang AG, Rao GS, Malik JK. Comparative plasma pharmacokinetics of meloxicam in sheep and goats following intravenous administration. Comparative Biochemistry and Physiology Part C: Toxicol Pharmacol 2007;145:528-32.

[27] Stafford KJ, Mellor DJ, Todd SE, Ward RN, McMeekan CM. The effect of different combinations of lignocaine, ketoprofen, xylazine and tolazoline on the acute cortisol response to dehorning in calves. New Zealand Vet J 2003;51:219-26

[28] Rincon M. Interleukin-6: from an inflammatory marker to a target for inflammatory diseases. Trends Immunol 2012;33:571-7.

[29] Rose-John S. Interleukin-6 biology is coordinated by membrane-bound and soluble receptors: role in inflammation and cancer. J Leukoc Biol 2006;80:227-36.

[30] Delannoy I, Lekeux P, Miossec P. Cytokine and anti-cytokine strategies in inflammatory reaction modulation. Vet Res, BMC 1993; 24:449-467.

[31] Brenn D, Richter F, Schaible HG. Sensitization of unmyelinated sensory fibers of the joint nerve to mechanical stimuli by interleukin- 6 in the rat: an inflammatory mechanism of joint pain. Arthritis Rheum 2007;56:3519.
[32] Fransson BA, Lagerstedt A-S, Bergstrom A, Hagman R, Park JS, Chew BP, et al. C-reactive protein, tumor necrosis factor $\alpha$, and interleukin- 6 in dogs with pyometra and SIRS. J Vet Emerg Crit Car 2007;17:373-81.

[33] El-Ghoul W, Hofmann W. Influence of claw diseases of varying degrees on measurable stress reactions with special consideration of cortisol and lactate in bovine blood serum. Praktische Tierarzt-Hannover 2002;83:354-61.

[34] Mudroň P, Rehage J, Sallmann HP, Höltershinken M, Scholz H. Stress Response in Dairy Cows Related to Different Blood Glucose. Acta Vet Brno 2005;74:37-42.

[35] Saini NS, Mohindroo J, Mahajan SK, Raghunath M, Kumar A, Sangwan V, et al. Surgical Correction of Uterine Torsion and Mare-Foal Survival in Advance Pregnant Equine Patients. J Equine Vet Sci 2013;33:31-4.

[36] Rizk A, Herdtweck S, Offinger J, Meyer H, Zaghloul A, Rehage J. The use of xylazine hydrochloride in an analgesic protocol for claw treatment of lame dairy cows in lateral recumbency on a surgical tipping table. Vet J 2012;192:193-8.

[37] Kilic N. Cardiopulmonary, biochemical and haematological changes after detomidinemidazolam-ketamine anaesthesia in calves. Bull Vet Inst Pulawy 2008;52:453-6.

[38] Chavhan S. Evaluation of Butorphanol-Acepromazine-Glycopyrrolate and Butorphanol-Midazolam Glycopyrrolate as Preanaesthetic with Propofol Anaesthesia in Dogs: MAFSU, Nagpur; 2014.

[39] Anandmay AK, Dass LL, Sharma AK, Gupta MK. Haemato-biochemical Changes Following Administration of Propofol in Combination with Buprenorphine in Atropinized Dogs. J Anim Res 2016;6:531.

[40] Khan M, Ashraf M, Pervez K, Hashmi H, Mahmood A. Effects of detomidine on blood chemistry and electrolyte profile in buffalo calves. Int J Agri Biol. 2003;5:308-10.

[41] Koichev K, Golemanov D, Houbenov H, Aminkov B. Experimental Study On The Effect of "Domosedan" in Sheep and Cattle. J AssocVet Anaes Great Britain and Ireland. 1988;15:114-26.

[42] Parrah J-u-D, Moulvi BA, Hussain SS, Bilal SJVa. Innovative tube cystostomy for the management of bovine clinical cases of obstructive urolithiasis. Veterinarski arhiv 2011;81:321-37. 